\title{
Article
}

\section{The IHAT-GUT Iron Supplementation Trial in Rural Gambia: Barriers, Facilitators, and Benefits}

\author{
Isabella Stelle ${ }^{1,2, * \mathbb{D}}$, Lorraine K. McDonagh ${ }^{3} \mathbb{D}$, Ilias Hossain ${ }^{4}$, Anastasia Z. Kalea ${ }^{1,5}, \mathbb{D}^{\mathbb{D}}$ and Dora I. A. Pereira ${ }^{4,6}$ \\ 1 Division of Medicine, Institute of Liver and Digestive Health, University College London (UCL), \\ London WC1E 6BT, UK \\ 2 Women and Children's Health Department, Division of Medicine, King's College London (KCL), \\ London SE1 7EH, UK \\ 3 Research Department of Primary Care and Population Health, University College London (UCL), \\ London NW3 2PF, UK; 1.mcdonagh@ucl.ac.uk \\ 4 Medical Research Council Unit the Gambia at the London School of Hygiene \& Tropical Medicine, Banjul, \\ The Gambia; mihossain@mrc.gm (I.H.); diap2@icloud.com (D.I.A.P.) \\ 5 Institute of Cardiovascular Science, University College London (UCL), London WC1E 6BT, UK \\ 6 Department of Pathology, University of Cambridge, Cambridge CB2 1QP, UK \\ * Correspondence: isabella.stelle@gmail.com (I.S.); a.kalea@ucl.ac.uk (A.Z.K.)
}

check for updates

Citation: Stelle, I.; McDonagh, L.K.; Hossain, I.; Kalea, A.Z.; Pereira, D.I.A The IHAT-GUT Iron Supplementation Trial in Rural Gambia: Barriers, Facilitators, and Benefits. Nutrients 2021, 13, 1140. https://doi.org/ $10.3390 /$ nu13041140

Academic Editor: James Swain

Received: 18 February 2021

Accepted: 27 March 2021

Published: 30 March 2021

Publisher's Note: MDPI stays neutra with regard to jurisdictional claims in published maps and institutional affiliations.

Copyright: (c) 2021 by the authors Licensee MDPI, Basel, Switzerland. This article is an open access article distributed under the terms and conditions of the Creative Commons Attribution (CC BY) license (https:// creativecommons.org/licenses/by/ $4.0 /)$.

\begin{abstract}
Introduction: In most sub-Saharan African countries iron deficiency anaemia remains highly prevalent in children and this has not changed in the last 25 years. Supplementation with iron hydroxide adipate tartrate (IHAT) was being investigated in anaemic children in a phase two clinical trial (termed IHAT-GUT), conducted at the Medical Research Council Unit the Gambia at the London School of Hygiene and Tropical Medicine (LSHTM) (abbreviated as MRCG hereof). This qualitative study aimed to explore the personal perceptions of the trial staff in relation to conducting a clinical trial in such settings in order to highlight the health system specific needs and strengths in the rural, resource-poor setting of the Upper River Region in the Gambia. Methods: Individual interviews $(n=17)$ were conducted with local trial staff of the IHAT-GUT trial. Data were analysed using inductive thematic analysis. Results: Potential barriers and facilitators to conducting this clinical trial were identified at the patient, staff, and trial management levels. Several challenges, such as the rural location and cultural context, were identified but noted as not being long-term inhibitors. Participants believed the facilitators and benefits outnumbered the barriers, and included the impact on education and healthcare, the ambitious and knowledgeable locally recruited staff, and the local partnership. Conclusions: While facilitators and barriers were identified to conducting this clinical trial in a rural, resource-poor setting, the overall impact was perceived as beneficial, and this study is a useful example of community involvement and partnership for further health improvement programs. To effectively implement a nutrition intervention, the local health systems and context must be carefully considered through qualitative research beforehand.
\end{abstract}

Keywords: anaemia; iron deficiency anaemia; iron deficiency; micronutrients; iron; clinical trial; nutrition intervention; public health; global health; malnutrition; low resource setting; qualitative

\section{Introduction}

\subsection{Iron Deficiency and the IHAT-GUT Trial in the Gambia}

Iron deficiency (ID) poses one of the most significant public health burdens today. At any given moment, more individuals suffer from ID than any other health problem, with an estimated 1.24 billion affected individuals worldwide [1]. ID is associated with multiple pathologies, including anaemia and defective organ function [2]. The prevalence of anaemia is five times higher in low- and middle-income countries (LMICs) than highincome countries, with $\sim 30 \%$ of the world's population, and $43 \%$ of $6-59$ months old children, being anaemic $[1,3]$. In Sub-Saharan Africa, $79 \%$ of children under six years are 
anaemic and iron deficiency anaemia (IDA) affects $58 \%$ of pre-school children [4]. As such, IDA is the largest international nutritional deficiency disorder and one of the five leading causes of global disease burden [1].

Despite widespread supplementation schemes, ID prevalence has not changed much in LMICs over the last 25 years [5]. There is growing interest in developing novel nanoiron compounds or delivery systems for fortification and supplementation [2,6-9]. One proposed strategy is a targeted-release nano-iron formulation [10]. Iron hydroxide adipate tartrate (IHAT) and standard-of-care ferrous sulphate were tested in a randomised placebocontrolled double-blind clinical trial (acronym IHAT-GUT) conducted at the Medical Research Council Unit the Gambia at the London School of Hygiene and Tropical Medicine (LSHTM) (abbreviated as MRCG hereof) [11].

\subsection{Nutrition Interventions in Varying Contexts and the Need for Qualitative Data}

While integrating nutrition-specific interventions into health systems can be impactful for both health and nutrition outcomes, different countries will have specific delivery needs for implementation [12]. Until the barriers and facilitators of nutrition intervention trials are studied across various settings, there will be a lack of data to implement such interventions. Additionally, LMICs remain underrepresented in research [13]. The Global Forum of Health Research termed this the "10/90 gap" to exemplify that less than $10 \%$ of health research funds go towards problems affecting $90 \%$ of the population worldwide [14], with a smaller percentage towards LMICs $[15,16]$. Evidently, clinical research is skewed, with more than $80 \%$ of clinical trials occurring in high-income countries [17-19] and only $~ 1 \%$ of drugs produced between 1975-2004 addressing LMIC issues [20]. Research enhancement in LMICs is an efficient and beneficial way to correct this gap [14].

\subsection{Clinical Nutrition Trials in LMICs}

Given the state of healthcare and disease prevalence in LMICs, clinical trials are well received, and participant recruitment is often easier than in a health secure country $[13,21]$. The ethical argument remains that medicines targeting conditions highly prevalent in LMICs should be tested in those populations, without transferring data from high-income settings. Interventions often have the largest impact medically in LMICs and benefit from involving local staff [22-24].

Difficulties of conducting clinical trials in LMICs stem from limitations in obtaining informed consent, ethical compensation mechanisms, poor health infrastructure, socioeconomic and cultural differences [21], and lack of education amongst study participants $[25,26]$. Additional barriers are limited research governance, funding, logistics, commercial ability, infrastructure, research materials, overall research capacity, and unsupportive administrative and government systems [15,16,25,27-30]. A recent review looking at existing integrated health and nutrition programmes across 45 LMIC settings found that service delivery and health workforce were well-integrated, but governance, information systems, finance and supplies, and technology were less well-integrated [12].

The aim of this study was to: qualitatively explore IHAT-GUT trial staff perceptions of barriers and facilitators to conducting this clinical trial to highlight the health system specific needs and strengths in a rural and resource-poor setting.

\section{Methods}

\subsection{IHAT-GUT}

IHAT-GUT was conducted on children with anaemia between the age of 6 and 35 months, living in The Upper River Region (URR) of the Gambia [11]. The children were enrolled in the trial for 113 days, within which they underwent supplementation for 85 days, with weekly study visits to test haemoglobin $(\mathrm{Hb})$ levels and malaria status, and three study timepoints included venous blood collection. Further information about IHAT-GUT study protocol is provided in the protocol paper [11]. 


\subsection{Study Setting}

We describe the involvement of research staff in the iron supplementation trial IHATGUT [11], which was under the governance of MRCG (Figure 1). The Gambia is the smallest and most densely populated country in West Africa, with about 2.28 million inhabitants, of which roughly one million (48.6\%) live below the national poverty line [31]. Islam is the predominant religion, polygamy is widely practiced, and families live in multigenerational compounds within villages [31]. The Gambia is subject to bimodal weather conditions having a "wet" (June to October) and "dry" (November to May) season. The seasonal rain determines the farming practices at that time of year, lending to extreme variations in seasonal diets and fluctuating levels of malnutrition [32].

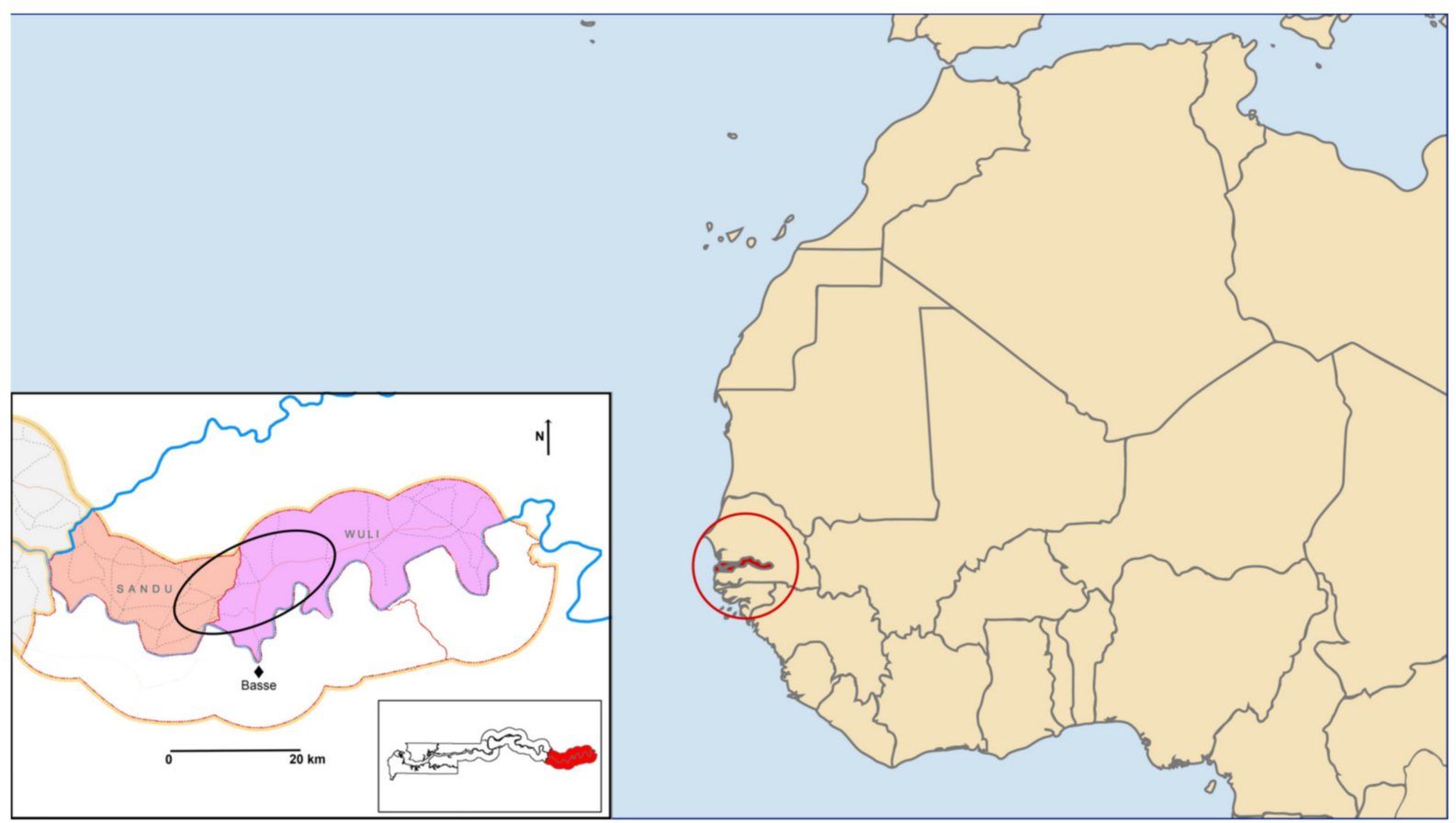

Figure 1. Study catchment area (circled in black) in the Upper River Region (red inset) of the Gambia (circled in red) in West Africa (main picture).

\subsection{Study Participants}

Individual interviews were conducted with 17 IHAT-GUT local trial staff (Table 1). Trial staff were purposively sampled to ensure insights from varying job types. To maintain anonymity, participants are identified via job title only.

\subsection{Data Collection}

Data was collected in person by the first author (IS). Participants chose the location of the interviews to facilitate a more comfortable environment. Locations included the MRCG in Basse and Fajara and study sites within the URR. A topic guide (available upon request) was developed and used to facilitate discussions. Interviews, with informed consent, were audio recorded and later transcribed verbatim. Photographs were taken during data collection with informed consent. Interviews continued until no additional insights were gained (i.e., data saturation [33]). 
Table 1. Demographic characteristics of sample.

\begin{tabular}{|c|c|c|}
\hline Demographics & $\mathbf{n}$ & $\%$ \\
\hline Ethnicity (Tribe) if applicable & & \\
\hline Gambian (Fula: Mandinka: Wolof: Banbara: Manjago) & $12(6: 3: 1: 1: 1)$ & 70 \\
\hline Other African Countries & 4 & 24 \\
\hline Other & 1 & 6 \\
\hline \multicolumn{3}{|l|}{ Religion } \\
\hline Muslim & 16 & 94 \\
\hline Christian & 1 & 6 \\
\hline \multicolumn{3}{|l|}{ Sex } \\
\hline Female & 1 & 17 \\
\hline Male & 16 & 83 \\
\hline \multicolumn{3}{|l|}{ Age (in years) } \\
\hline $18-29$ & 1 & 17 \\
\hline $30-39$ & 6 & 26 \\
\hline $40-49$ & 7 & 30 \\
\hline $50-59$ & 3 & 13 \\
\hline \multicolumn{3}{|l|}{ Highest Level of Education } \\
\hline Secondary School & 5 & 29 \\
\hline State Enrolled Nursing School & 3 & 18 \\
\hline Bachelors & 1 & 5 \\
\hline Medicine Degree & 3 & 18 \\
\hline Masters & 3 & 18 \\
\hline Doctorate $^{\text {a }}$ & 2 & 12 \\
\hline \multicolumn{3}{|l|}{ Years Employed with MRCG ${ }^{\mathrm{b}}$ Projects } \\
\hline $0-5$ & 3 & 18 \\
\hline $6-10$ & 6 & 35 \\
\hline $11-15$ & 3 & 18 \\
\hline $16-20$ & 4 & 23 \\
\hline $21-25$ & 0 & 0 \\
\hline $25-30$ & 1 & 6 \\
\hline
\end{tabular}

$\mathrm{a}=$ one in progress. $^{\mathrm{b}}=$ MRC Unit the Gambia

\subsection{Data Analysis}

Transcripts were analysed using inductive thematic analysis to explore patterns in the data [34]. Braun and Clarke's six phases of thematic analysis were used (Table 2) [34]. The transcripts were read several times (data familiarisation). Notes were made in relation to significant and/or interesting comments made by interviewees. The transcripts were coded, and memos written. A code represented a feature of the data that the researcher found interesting or insightful in relation to the research questions, and the memo was a summary of the findings [34]. A list of codes was constructed and connections between them sought to develop provisional themes (repeated patterned responses within data sets) and sub-themes [34]. When all transcripts were analysed, a final list of themes and sub-themes was created.

Table 2. Six phases of thematic analysis adapted from Braun and Clarke (2006).

\begin{tabular}{cr}
\hline Phase & Description \\
\hline \begin{tabular}{cc} 
1. Data Familiarization & Transcribing, reading, and re-reading data \\
\hline 2. Initial Codes & Coding interesting features systematically and collating the data to each code \\
\hline 3. Theme Development & Collating codes into potential themes and adding relevant data to each \\
\hline $\begin{array}{c}\text { 4. Refining Themes } \\
\text { 5. Naming Themes }\end{array}$ & Ensuring themes work with the first (data familiarization) and second (initial \\
codes) levels of analysis
\end{tabular} \\
\hline 6. The Report & Final analysis opportunity, extraction of compelling examples
\end{tabular}

An inductive approach was used whereby data analysis was data driven so that participant's views took precedence over the interviewer's previous knowledge or beliefs [34]. That said, previous knowledge will, to some extent, influence the research. Therefore, to 
ensure rigour and validate the finding, transcripts were analysed by the second author (LMD) using the same procedure. Discrepancies were discussed and jointly altered.

\subsection{Ethical Considerations}

Ethical approval was obtained from the Gambia Government/MRC Joint Ethics Committee (REF: L2018.25) in June 2016. The study was conducted in accordance with the Declaration of Helsinki. Written and verbal informed consent for interviews and photographs was obtained from each participant. It was made clear that refusal to be involved would be confidential and would not affect their work; no participants refused to be interviewed.

\section{Results}

A distinction was made between barriers and facilitators at three levels: study participant, trial staff, and trial management.

\subsection{Barriers}

The barriers included community factors and low incentivisation (participant level), motivation (staff level), and country context (trial management level) (Figure 2). Illustrative quotes from each sub-theme of the barriers can be found in Table 3.

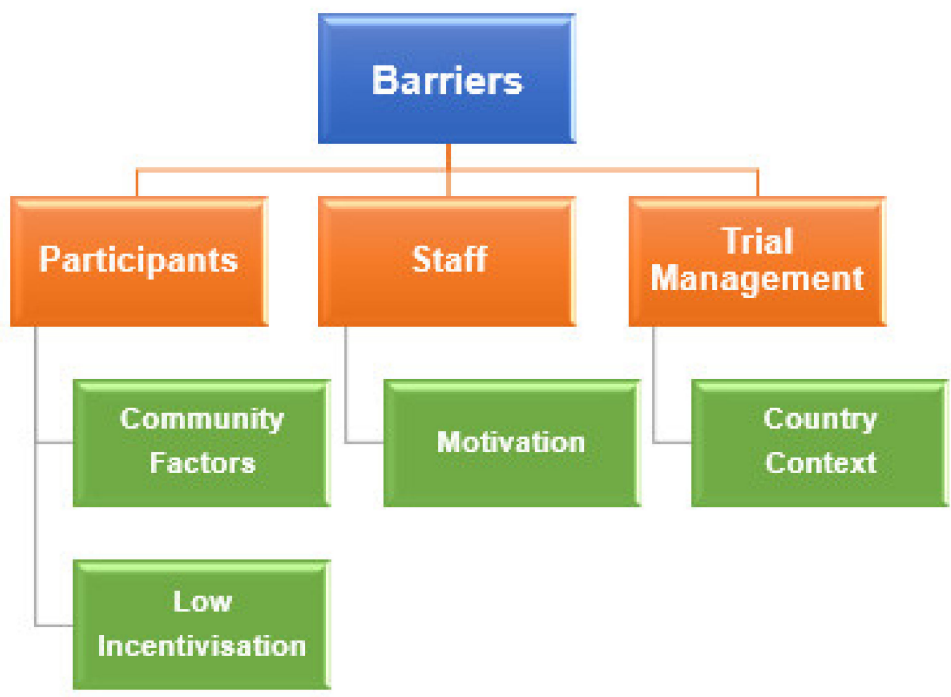

Figure 2. Graphical illustration of themes and sub-themes of the barriers.

Table 3. Illustrative quotes for each sub-theme of the barriers.

\begin{tabular}{|c|c|c|}
\hline Theme & Sub-Theme & Illustrative Quote \\
\hline \multirow[t]{2}{*}{ Participants } & Community Factors & $\begin{array}{c}\text { "There's also a bit of cultural problem ... because in Africa we believe the wife stays } \\
\text { home to cook, clean. So, some husbands decide (to) have their wives stop going to the } \\
\text { clinic visits."-Data Manager }\end{array}$ \\
\hline & Low Incentivisation & $\begin{array}{l}\text { "We take blood from these children, so we need to make life easy for them. Maybe they } \\
\text { are on the drug that doesn't do anything."-State Enrolled Nurse } 2\end{array}$ \\
\hline Staff & Motivation & $\begin{array}{c}\text { "There will always be challenges. That you should expect. The biggest challenge is } \\
\text { working with individuals and managing individuals. Everyone has negative qualities, } \\
\text { I have them."-Research Clinician }\end{array}$ \\
\hline $\begin{array}{c}\text { Trial } \\
\text { Management }\end{array}$ & Country Context & $\begin{array}{c}\text { "The major challenges in running these trials here is the start up. Making all the } \\
\text { necessary arrangements. The necessary approvals from the Ministry, from the } \\
\text { Medicine Control Agency, from the Ethics and SCC (Scientific Coordinating } \\
\text { Committee), establishing the sites of the studies and so forth. And of course, it requires } \\
\text { a lot of logistical support... especially if they are in remote areas. IHAT-GUT is } \\
\text { running its study where no study has been done in the past at this scale... (and) } \\
\text { during rainy season you have floods."-Project Manager }\end{array}$ \\
\hline
\end{tabular}




\subsubsection{Participants}

Community Factors

Many viewed specific cultural factors as barriers to successful running of this trials, specifically community hierarchies and education. These issues posed challenges with community sensitisation for the staff, but it was noted that these barriers were easily overcome if approached properly. Regarding hierarchies, the Local principal investigator (PI) noted that to run the trial fluidly it was key to "pass the messages [to the communities] smoothly, so everyone can understand. If your communities understand you won't have problems ... with sensitisation go through the hierarchy: the village level, then compound level, then houses, then individuals". Another community norm is that mothers often stay home and mind the children and household, but during IHAT-GUT, mothers and children had to attend clinic once a week. The Data Manager stated: "There's also a bit of cultural problem ... because in Africa we believe the wife stays home to cook, clean. So, some husbands decide (to) have their wives stop going to the clinic visits". The issue of husbands not wanting their wives to leave home to attend clinic visits was a barrier to participant recruitment, but with appropriate informed consent and village hierarchical involvement, this was overcome.

Community education levels were believed to impact the communication of trial information. While many men attend secondary school, women often leave school during puberty to start a family. The low level of education was viewed as a barrier to informing communities about the trial: "The level of awareness, literacy and education here is a challenge because you want to be sure that the people you are conducting research on are aware of what your study is about and what the implications are" (Research Clinician). Another barrier was the misunderstanding about blood sampling. State Enrolled Nurse 1 pointed out that some parents were reluctant for their child to join the trial (and others withdrew) when they learnt blood drawing was involved (Figure 3). This was linked to lack of education and local attitudes towards confusion around clinical research: "Sometimes the awareness is an issue, some people have the wrong sentiment with the local mindset" (Data Manager). To overcome this barrier, IHAT-GUT used village sensitisation to inform all villagers about the trial and of what it consisted.

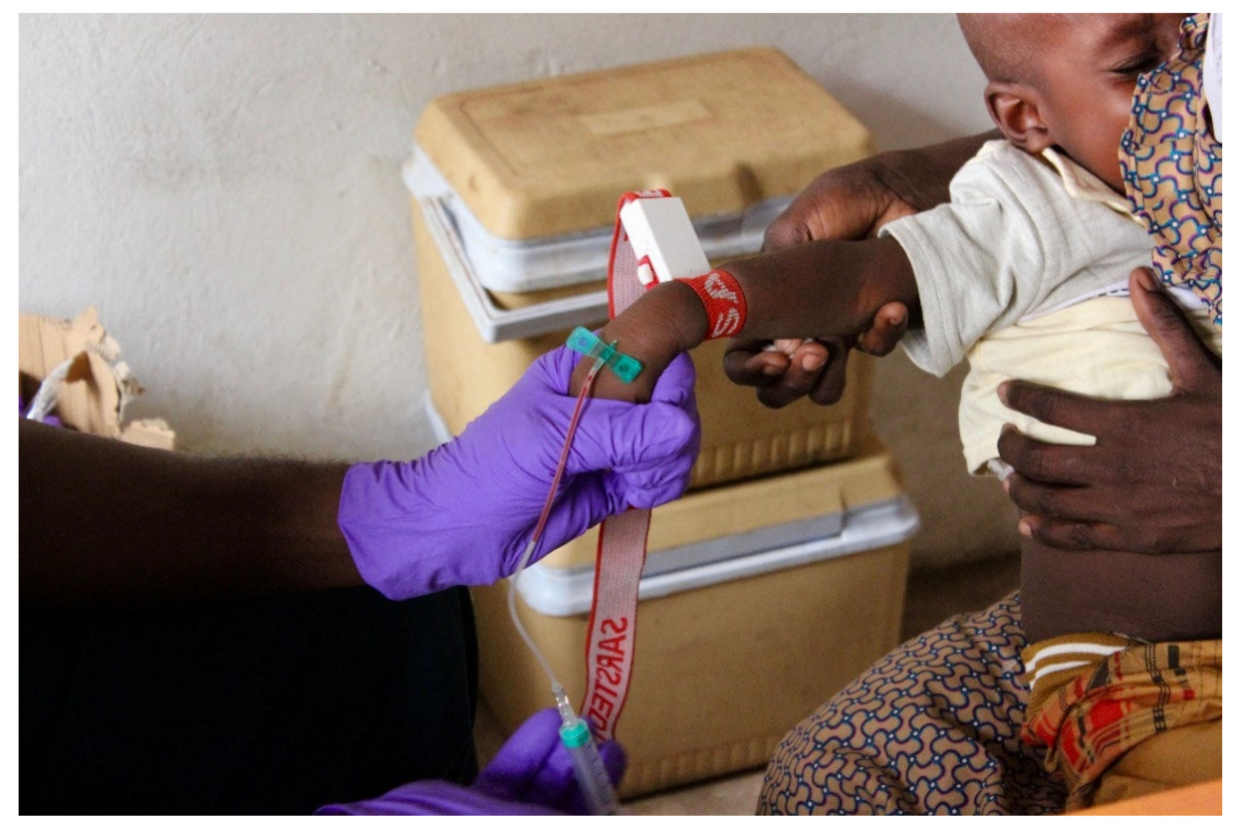

Figure 3. Photograph of blood drawing during a visit to the study clinic.

Low Incentivisation

State Enrolled Nurse 2 maintained that offering free medication and healthcare was an incentive to take part in the trial but moving forward researchers in other clinical trials need to consider incentives beyond the child's healthcare: "When we do the venous bleeding, 
we give them (the mothers) 50 Dalasis (to buy breakfast), but I would love for it to be more than that. We take blood from these children, so we need to make life easy for them. Maybe they are on the drug that doesn't do anything. The mothers sacrifice a lot for this project, so we need to give them something back".

\subsubsection{Staff}

Motivation

As summarised by the Research Clinician, there is always challenges when working within teams: "There will always be challenges. That you should expect. The biggest challenge is working with individuals and managing individuals. Everyone has negative qualities, I have them". Workload was also noted as a barrier by both the laboratory and data teams, as those departments "tend to be oversubscribed" (Statistician). The Analytical Project Manager commented that the workload became unmanageable for the laboratory staff at some points. Staff motivation was difficult for those with managerial responsibilities (See Supplementary Figure S1): "Although this is not the first time, I've manned a group like this, it's not easy" (Field Coordinator; managed thirty employees).

\subsubsection{Trial Management \\ Country Context}

The remote setting and harsh weather conditions required extensive planning and coordination: "Resources are always a problem in developing countries" (Statistician). Likewise, "IHAT-GUT is running its study where no study has been done in the past at this scale ... during rainy season you have floods" (Nutrition Theme Administrator). The Research Clinician mentioned that: "The weather ... it's harsh, it's quite hot, dusty, you get flooding". It was also mentioned that: "You need to consider the environment and circumstance (they) are in a very robust area in the North Banks" (Local PI) where "the villages are far, and the roads are poor" (Senior Field Worker). For example, "let's say you're living in a place like Kuwonkuba, they might not have electricity or clean water. This adds stress" (State Enrolled Nurse 1).

The Nutrition Theme Administrator noted that the context made sticking to the tight project timelines challenging: "The major challenges in running these trials here is ... making all the necessary arrangements: approvals from the Ministry, Medicine Control Agency, Ethics and SCC (Scientific Coordinating Committee), establishing the sites of the studies. And of course, it requires a lot of logistical support in remote areas". He also noted handling the "financial management" of various projects at MRCG in relation to context: "Always expect a project to overrun, so you adequately allocate expenditures. For example, in clinical trials, you always have SAEs (Serious Adverse Events)". The associated expenditures due to the context also posed a challenge for the Field Coordinator: "It's a problem ... we are spending too much on the (ferry) crossing". Likewise, transporting mothers from villages to clinics and transferring samples to the main laboratory facilities added financial stress. The Senior Field Worker noted funding needs such as giving "(phone) credit to call for the Field Workers and mothers" so they could afford to make trial related calls.

\subsection{Facilitators $\mathcal{E}$ Benefits}

The facilitators included healthcare, incentivisation, and receptive communities (participant level); staff characteristics and education enhancement (staff level); and the local partnership (trial management level) (Figure 4). Illustrative quotes from each sub-theme of the facilitators can be found in Table 4 . 


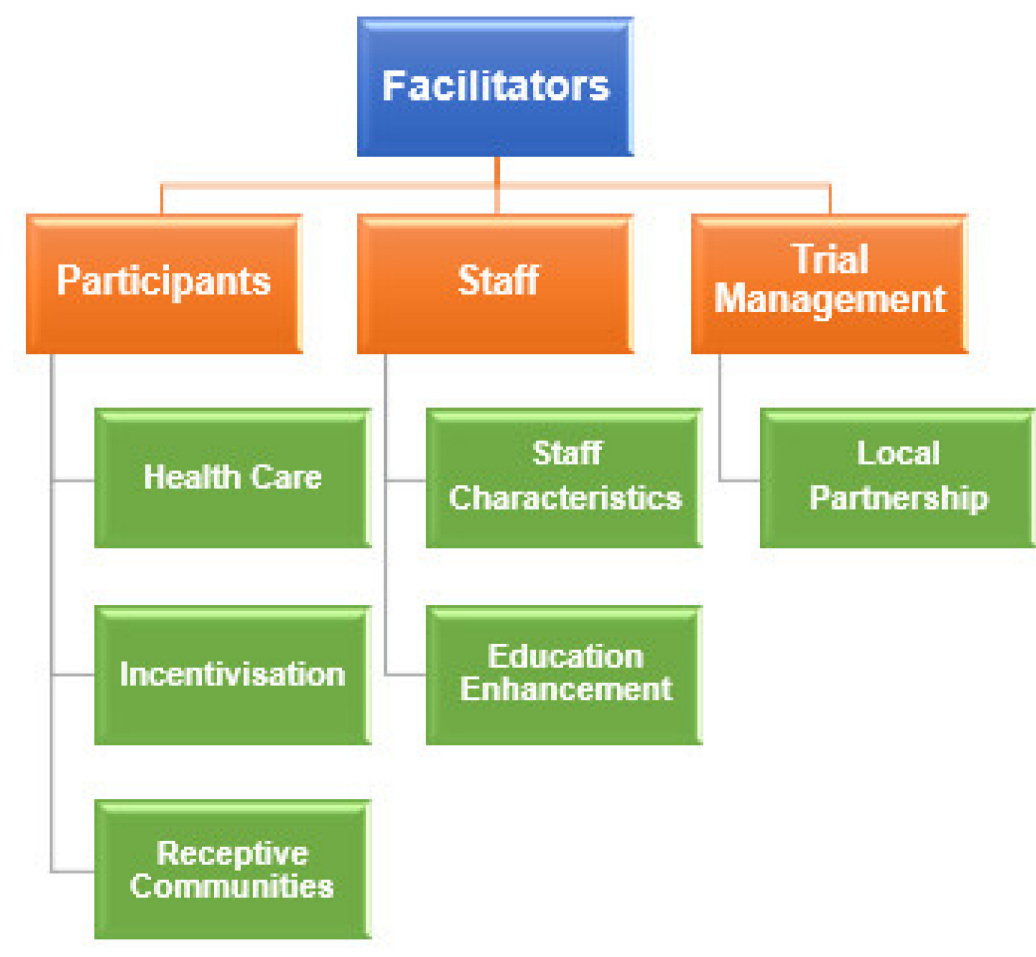

Figure 4. Graphical illustration of themes and sub-themes of the facilitators.

Table 4. Illustrative quotes for each sub-theme of the facilitators.

\begin{tabular}{|c|c|c|}
\hline Theme & Sub-Theme & Illustrative Quote \\
\hline \multirow[t]{3}{*}{ Participants } & Health Care & $\begin{array}{l}\text { "IHAT-GUT ... helps the Gambian children and it's the first one in the } \\
\text { North Bank... We are working where they need it most... There was more } \\
\text { anaemia, they had less hospitals. Medical care is lacking. Mothers say: } \\
\text { 'please come to our communities'." - Senior Field Worker }\end{array}$ \\
\hline & Incentivisation & $\begin{array}{c}\text { "You need to bring a social impact, so the participants feel valued (rather) } \\
\text { than just coming to do what you want and not giving the mothers and } \\
\text { children something."-Data Manager }\end{array}$ \\
\hline & Receptive Communities & $\begin{array}{c}\text { "The Gambians, they are remarkable people. They are the most amazing, } \\
\text { welcoming people. It's a very friendly environment to work in. It's a } \\
\text { research-friendly country."-Research Clinician }\end{array}$ \\
\hline \multirow[t]{2}{*}{ Staff } & Staff Characteristics & $\begin{array}{l}\text { "In Europe, I don't think it would be easy to conduct studies like this. In } \\
\text { Africa, people don't find it a problem that projects come in their } \\
\text { communities. We are Gambian. When we go into our own communities, } \\
\text { they are accepting."-Senior Field Worker }\end{array}$ \\
\hline & Education Enhancement & $\begin{array}{c}\text { "The Nutritional Course was great. It added value because it not only } \\
\text { taught us about nutrition personally, but on the other hand, it's great to do a } \\
\text { team activity. It makes everyone feel appreciated... You want to develop the } \\
\text { staff."-Data Manager }\end{array}$ \\
\hline Trial Management & Local Partnership & $\begin{array}{l}\text { "MRC has a great track record here in the Gambia, they have cordial } \\
\text { relationships with the communities and with The Gambian government and } \\
\text { its ministries."-Nutrition Theme Administrator }\end{array}$ \\
\hline
\end{tabular}

\subsubsection{Participants}

Healthcare

The study was conducted in the North Bank of the URR where the poorest Gambian communities reside and the double burden of malnutrition and infection is highest [35]. Scientific Officer 2 noted: "It's better to give nutritional interventions where they are most 
needed". This was echoed by the Senior Field Worker: "Especially IHAT-GUT because it helps the Gambian children and it's the first one in the North Bank... We are working where they need it most...There was more anaemia, they had less hospitals. Medical care is lacking. Mothers say: 'please come to our communities'".

Another advantage for trial participants was that healthcare was fully covered during the trial. The Nurse Coordinator found that local communities embraced these interventions: "These studies excite them. They want them to continue. We deal with the health, the management, the transportation."

Incentivisation

The Data Manager mentioned that: "You need to bring a social impact, so the participants feel valued (rather) than just coming to do what you want and not giving the mothers and children something". A successful incentive was the provision of Yandi juice, which made supplement administration easier and more enjoyable for participants: "Giving the Yandi attracts the children because they want to take the drugs. When they see the Field Workers, they get excited" (State Enrolled Nurse 2). The Nurse Coordinator also mentioned how "sometimes the kids are running for the Fields Workers because they are excited for the juice" and advised to use this approach in the future.

Receptive Communities

Staff found the communities were receptive towards the study. The Research Clinician, who is not Gambian himself, found: "The Gambians, they are remarkable people. They are the most amazing, welcoming people. It's a very friendly environment to work in. It's a researchfriendly country". State Enrolled Nurse 2 highlighted that URR, being a low resource setting, facilitated this: "The advantage of the project being run here is due to low-income earners, so having these projects is a big deal ... They are very cooperative. In an urban area it would have been harder, but in a rural area they are excited". The Data Manager echoed this sentiment and believed a similar trial in the UK would be more challenging.

\subsubsection{Staff}

\section{Staff Characteristics}

It was very helpful that the staff going into the communities to conduct research were from a similar cultural background and could speak local languages. The Senior Field Worker highlighted: "In Europe, I don't think it would be easy to conduct studies like this. In Africa, people don't find it a problem that projects come in their communities. We are Gambian. When we go into our own communities, they are accepting".

The staff had strong experience and knowledge in working with research studies in rural Gambia. The Local Safety Monitor was confident that being part of this project meant having a high calibre of staff with education, knowledge, and experience: "The teams, the doctors, the researchers, the nurses and so on that we have here are second to no other country, so you know they can get good work here". The Analytical Project Manager had the same confidence in his colleagues: "It's also that they have people on ground who already have experience of running these clinical trials, both from the clinical aspects to the field staff. The people are experienced and consistent (...) they have had proper training about interacting with the community and attaining data from them".

Staff were highly ambitious for themselves and the development of their country. The Local Safety Monitor mentioned impacting West Africa through public health: "(It's) very important to me because it drives you to continue your work, you see the issues and the results and it's inspiring to keep doing this work". Having grown up in the Gambia, the Data Manager was proud to impact his country: “Growing up here, I've always seen malnutrition and poverty, so I'm conscious of my country's state ( . . ) you are contributing to change young people's lives, which is just amazing". Likewise, the Senior Field Worker found: " . . I can contribute my part to help Gambian children". 


\section{Education Enhancement}

The staff felt valued by MRCG and IHAT-GUT, thanks to the knowledge that they gained and this enriched their work experience and dedication to the trials (See Supplementary Figure S2). The Field Worker was proud of his personal learning and was grateful for the educational opportunities: "One thing I like in IHAT-GUT is the blood experience because it's a learning experience". One of The Statistician's favourite parts of working with MRCG was their advancement of staff knowledge through training. Likewise, Scientific Officer 2 was able to complete her master's because of MRCG.

\subsubsection{Trial Management}

\section{Local Partnership}

MRCG's research unit has been in the Gambia for 70 years, giving them respect in the country for their long-standing establishment, advances in healthcare, and facilities for epidemiological studies and clinical trials. MRCG's upstanding reputation with The Gambian Government and communities allowed easier collaboration and authorisation from the government: "MRC has a great track record here in the Gambia, they have cordial relationships with the communities and with The Gambian government and its ministries" (Nutrition Theme Administrator). The Field Coordinator noted that MRCG has an international research reputation: "They have a high regard in terms of quality research, and they have been in existence for almost 70 years" (See Supplementary Figure S3). The Analytical Project Manager was grateful for the high-quality facilities, which allowed the project to run smoothly (Figure 5).

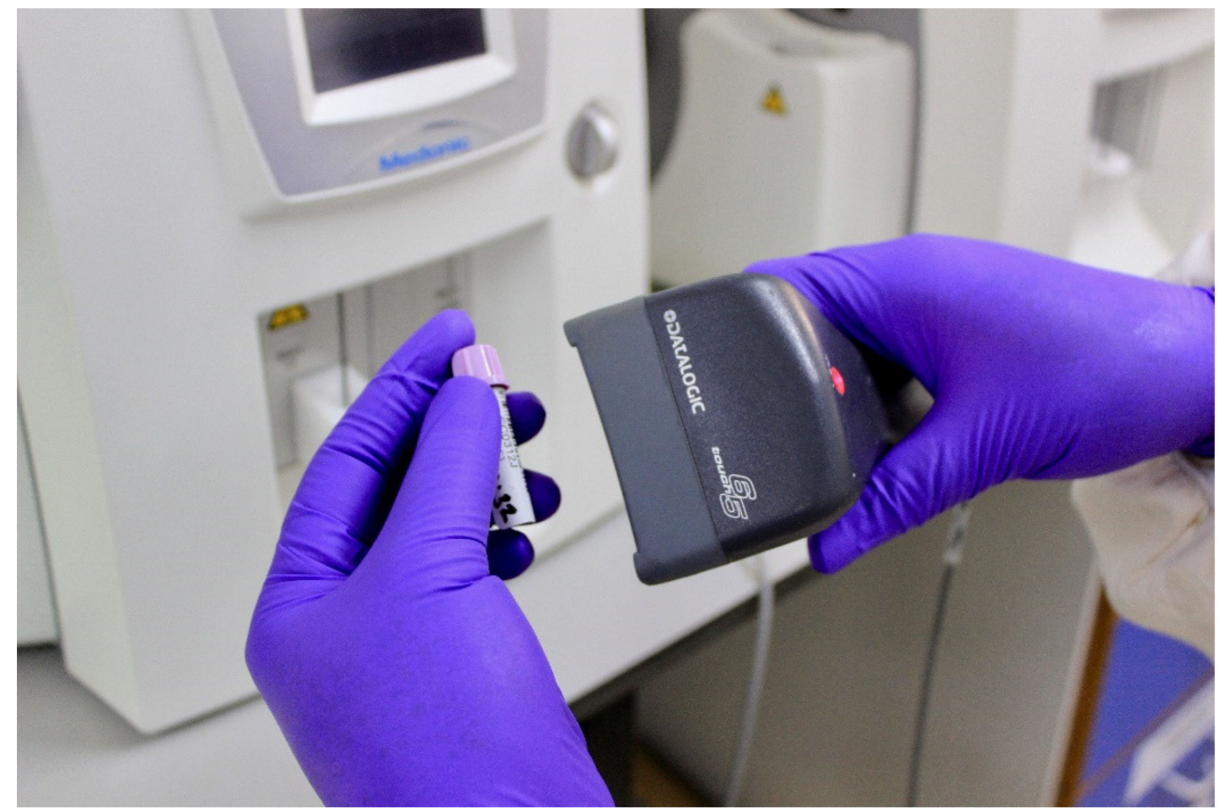

Figure 5. Photograph of sample processing done to Good Clinical Lab Practice standards.

\section{Discussion}

Clinical research in a LMIC, such as the Gambia, poses challenges. Barriers emerged in this study, such as mistrust regarding blood drawing. $\mathrm{O}^{\prime} \mathrm{Neill}$ et al. [26] looked at the misconceptions around blood and its impacts on trial participation in a village in rural Gambia. Originally, participant recruitment for finger-pricking for posed no problem, but as soon as rumours about the use of the blood and concerns around the health implications of blood loss started spreading, only $42 \%$ of the inhabitants consented [26]. They concluded that to overcome this barrier one must better inform and educate the villagers [26]. Likewise, as noted in the literature and concurrent with our findings, in order to facilitate clinical trials, health education is crucial to avoid misconceptions about diseases in the Gambia [25]. 
While LMICs were noted as lacking commercial ability, infrastructure, materials, and overall research capacity, elsewhere, this was not seen in the present study $[15,16,27]$. Running clinical trials through MRCG appeared as a facilitator, while unsupportive administrative systems were reported to be a barrier for clinical trials in LMICs [27,28]. In terms of "human capacity," a recurrent theme in this data was the experienced MRCG staff and investment in training. In contrast, Ross et al. [33] found that in developed countries, such as the United States, United Kingdom, Europe, and Australia, lack of staff and adequate training posed barriers. Likewise, in our study staff motivation was noted as occasionally posing a barrier, which is concurrent with the literature $[27,36]$.

Materials can be difficult to resource in LMICs and for projects to run smoothly; advanced planning is needed. However, a lack of resources in LMICs increases the need for sound research to prioritise these limitations [37]. This barrier of planning and preparation not only encompasses the materials needed, but also appropriate government approvals, which was previously noted $[27,36]$. MRCG's long-standing establishment and good government relations ease this potential barrier due to expediated government and ethical approvals as well as familiarity with product procurement in a resource-limited setting. Overall, the participants showed a clear awareness of the country contexts' barriers and facilitators, and the implications these have for the trial. Going forward, building research capacity by conducting more clinical trials in LMICs is vital to ease the burden of what are already rigorous and time-consuming study preparation phases, only complicated by the resource limitations of LMICs.

The overall impact for the country's healthcare can be beneficial and outweighs the barriers described. Our findings are in line with previous research, noting the need for research in such communities $[13,21]$. Clinical interventions in LMICs have the largest impact in decreasing childhood mortality rates $[13,21]$. The high infection burden setting of rural Gambia was the ideal setting for IHAT-GUT. If the drug were to be tested in a high-income, low-infection burden country, its effects might not be translatable to the country of target, as seen in other clinical trials [38,39].

The ease in recruiting patients was noted as a facilitator in running clinical trials in LMICs like the Gambia. LMICs offer an attractive setting for clinical trials as there is often less access to healthcare, so the prospect of healthcare through a clinical trial lends to shorter periods of participant recruitment [21]. Recruitment time can be five to ten times quicker in LMICs than in developed regions such as the United States or Europe [30]. For example, one participant highlighted that he did not think mothers in developed countries would be happy to enrol their child in a study, but in the Gambia the mothers are willing. Ross et al. [33] similarly reported in his systematic review of 78 randomized control trials across the United States, United Kingdom, Europe, and Australia that recruitment for clinical trials was a challenge. Overall, the staff's observations about the trial setting being a facilitator for participant incentivisation and ease of recruitment due to increased access to healthcare is in agreement with previous literature.

Thanks to the local partnership and strong establishment of MRCG in the Gambia, the country is well equipped for incoming projects due to receptive communities, ambitious and knowledgeable locally recruited staff, and the research facilities and governance offered by MRCG. Locally recruited staff working in their own communities made communities receptive to the trial due to increased trust. It was previously reported that it was beneficial for clinical trials to utilise their local workforce because it allowed for the use of local knowledge [22]. This made the trials more responsive to the country's needs and more effective in influencing policy [24]. Likewise, the staff were aware that passing knowledge through the family hierarchies may facilitate participant recruitment. Preliminary community sensitisation that allowed information to be passed through the appropriate village hierarchy in the Gambia has been successful in the past [23].

Another highlighted facilitator in the trial, beyond just participant healthcare, was participant transportation to and from the clinic where the interventions took place. Mobility has been seen as a barrier for non-participation in a clinical trial in the Gambia [25,29]. 


\section{Limitations}

A few limitations of this study warrant noting. Data was collected by a young white woman interviewing mostly older men. Broom et al. [40] found heightened "professionalism" and self-credentialing by men when interviewed by a woman. Likewise, it has been noted that gender in research warrants more attention, especially in the context of women interviewing men, such as men's assertions of gender identities and gender hierarchy [41]. Additionally, the PI (IS) worked closely with the PI of IHAT-GUT (DIAP) and an association of the two women being colleagues may have influenced participant answers due to concern around socially desirable responding in high-stakes situations where participants aim to make a good impression [42]. Lastly, IHAT-GUT was noted to be well run, using different monitoring, training and consenting systems that have not been used by a study in those communities before. Therefore, facilitators may have been more prominent [27], making it harder to relate to other clinical trials.

\section{Conclusions}

This study highlighted the barriers and facilitators to conducting this clinical trial in a rural and resource-poor setting. It brought to light that for clinical trials to be successful in such settings, cultural context must be carefully considered. Specifically, researchers should devote substantial time to engaging with the community to gain insight into pre-existing beliefs, knowledge, and awareness levels of the population, as well as the social structures at play.

This study reported that the staff were proud of their high calibre of work and ambitious to continue making an impact on the country's education and healthcare levels. While barriers were faced in running a clinical trial in this rural, resource-poor setting, the overall impact was perceived as beneficial, and this study is a useful example of community involvement and partnership for further health improvement programs. These findings highlight the value that staff find clinical trials add to their lives as well as the need for creating and nurturing local partnerships, which enables the continuous embrace and success of clinical research.

Supplementary Materials: The following are available online at https://www.mdpi.com/article/ 10.3390/nu13041140/s1, Figure S1: Photograph of members of the IHAT-GUT field team. Figure S2: Photograph of the poster session at the Nutrition Workshop. Figure S3: Photograph of Driver and Nurse Coordinator picking up a participant and mother from their home for evaluation of an adverse event.

Author Contributions: I.S. conducted the research for this project. D.I.A.P. and A.Z.K. conceived and designed the study. I.S., I.H. and D.I.A.P. coordinated the fieldwork. L.K.M. coordinated the data analysis. I.S. conducted the field work, did the initial analyses of the data, and wrote the draft manuscript. All authors commented on data interpretation/visualisation and edited and reviewed the manuscript. All authors have read and agreed to the published version of the manuscript.

Funding: I.S. was partly supported by a travel bursary from University College London. D.I.A.P. and the IHAT-GUT trial were supported by a Bill and Melinda Gates Foundation Grand Challenges New Interventions for Global Health award (OPP1140952). The Nutrition Workshop was supported by the Cambridge-Africa Alborada Research Fund. The Nutrition Group of the MRC Unit the Gambia at LSHTM were supported by core funding MC-A760-5QX00 to the MRC Unit the Gambia/MRC International Nutrition Group by the UK MRC and the UK Department for the International Development (DFID) under the MRC/DFID Concordat agreement. The funders had no role in study design, field data collection and analysis, decision to publish, or preparation of this manuscript.

Institutional Review Board Statement: The study was conducted according to the guidelines of the Declaration of Helsinki, and approved by the Gambia Government/MRC Joint Ethics Committee (REF: L2018.25) in June 2016.

Informed Consent Statement: Informed consent was obtained from all subjects involved in the study.

Data Availability Statement: All relevant data are reported within the manuscript. 
Acknowledgments: The authors thank the committed IHAT-GUT staff for their support of this research and for taking part in this qualitative study. We also thank the children and mothers of the IHAT-GUT study for allowing us to shadow them during their study visits and for their willingness to participate in research studies to further scientific knowledge and health. Finally, we thank the local communities of the North Bank in the URR for agreeing to this study taking part in their villages.

Conflicts of Interest: D.I.A.P. is one of the inventors of the IHAT iron supplementation technology, for which she could receive future awards to inventors through the MRC Awards to Inventor scheme. D.I.A.P. has served as a consultant for Vifor Pharma UK, Entia Ltd., Shield Therapeutics, Danone Nutritia, UN Food and Agriculture Organisation (FAO) and Nemysis Ltd. DIAP now works for Vifor Pharma UK, but all work pertaining to this publication was conducted whilst at the University of Cambridge and MRC Unit the Gambia at LSHTM. Notwithstanding, the authors declare no potential conflicts of interest with respect to the research, authorship, and/or publication of this article.

Disclaimers: All authors have read and approved the final version of the manuscript for publication. The opinions expressed in this article are the participants and authors' own and do not reflect necessarily the view of their affiliated institutions and corporations.

$\begin{array}{ll}\text { Abbreviations } \\ \text { DNA } & \text { Deoxyribonucleic acid } \\ \text { GCP } & \text { Good Clinical Practice } \\ \text { Hb } & \text { Haemoglobin } \\ \text { ID } & \text { Iron deficiency } \\ \text { IDA } & \text { Iron deficiency anaemia } \\ \text { IHAT } & \text { Iron hydroxide adipate tartrate } \\ \text { LMIC } & \text { Low-middle income country } \\ \text { LSHTM } & \text { London School of Hygiene and Tropical Medicine } \\ \text { mL } & \text { Millilitre } \\ \text { MRC } & \text { Medical Research Council } \\ \text { MRCG } & \text { Medical Research Council Unit, the Gambia } \\ \text { MSc } & \text { Master of Science } \\ \text { PI } & \text { Principal investigator } \\ \text { SCC } & \text { Scientific Coordinating Committee } \\ \text { UK } & \text { United Kingdom } \\ \text { URR } & \text { Upper River Region } \\ \text { WHO } & \text { World Health Organisation }\end{array}$

\section{References}

1. GBD 2016 Disease and Injury Incidence and Prevalence Collaborators. Global, regional, and national incidence, prevalence, and years lived with disability for 328 diseases and injuries for 195 countries, 1990-2016: A systematic analysis for the Global Burden of Disease Study 2016. Lancet 2017, 390, 1211-1259. [CrossRef]

2. Prentice, A.M.; Mendoza, Y.A.; Pereira, D.; Cerami, C.; Wegmuller, R.; Constable, A.; Spieldenner, J. Dietary strategies for improving iron status: Balancing safety and efficacy. Nutr. Rev. 2017, 75, 49-60. [CrossRef]

3. Miller, J.L. Iron deficiency anemia: A common and curable disease. Cold Spring Harb. Perspect. Med. 2013, 3. [CrossRef] [PubMed]

4. World Health Organization. Worldwide Prevalence of Anaemia 1993-2005: WHO Global Database on Anaemia; De Benoist, B., McLean, E., Egli, I., McLean, E., Eds.; World Health Organization: Geneva, Switzerland, 2008.

5. Stelle, I.; Kalea, A.Z.; Pereira, D.I.A. Iron deficiency anaemia: Experiences and challenges. Proc. Nutr. Soc. 2018, 1-8. [CrossRef]

6. Hilty, F.M.; Arnold, M.; Hilbe, M.; Teleki, A.; Knijnenburg, J.T.N.; Ehrensperger, F.; Hurrell, R.F.; Pratsinis, S.E.; Langhans, W.; Zimmermann, M.B. Iron from nanocompounds containing iron and zinc is highly bioavailable in rats without tissue accumulation. Nat. Nanotechnol. 2010, 5, 374-380. [CrossRef]

7. Pisani, A.; Riccio, E.; Sabbatini, M.; Andreucci, M.; Del Rio, A.; Visciano, B. Effect of oral liposomal iron versus intravenous iron for treatment of iron deficiency anaemia in CKD patients: A randomized trial. Nephrol. Dial. Transplant. 2014, 30, 645-652. [CrossRef]

8. Powell, J.J.; Bruggraber, S.F.; Faria, N.; Poots, L.K.; Hondow, N.; Pennycook, T.J.; Latunde-Dada, G.O.; Simpson, R.J.; Brown, A.P.; Pereira, D.I. A nano-disperse ferritin-core mimetic that efficiently corrects anemia without luminal iron redox activity. Nanomedicine 2014, 10, 1529-1538. [CrossRef] [PubMed] 
9. Von Moos, L.M.; Schneider, M.; Hilty, F.M.; Hilbe, M.; Arnold, M.; Ziegler, N.; Mato, D.S.; Winkler, H.; Tarik, M.; Ludwig, C.; et al. Iron phosphate nanoparticles for food fortification: Biological effects in rats and human cell lines. Nanotoxicology 2017, 11, 496-506. [CrossRef] [PubMed]

10. Pereira, D.I.; Bruggraber, S.F.; Faria, N.; Poots, L.K.; Tagmount, M.A.; Aslam, M.F.; Frazer, D.M.; Vulpe, C.D.; Anderson, G.J.; Powell, J.J. Nanoparticulate iron(III) oxo-hydroxide delivers safe iron that is well absorbed and utilised in humans. Nanomedicine 2014, 10, 1877-1886. [CrossRef] [PubMed]

11. Pereira, D.I.; Mohammed, N.I.; Ofordile, O.; Camara, F.; Baldeh, B.; Mendy, T.; Sanyang, C.; Jallow, A.T.; Hossain, I.; Wason, J.; et al. A novel nano-iron supplement to safely combat iron deficiency and anaemia in young children: The IHAT-GUT double-blind, randomised, placebo-controlled trial protocol. Gates Open Res. 2018, 2, 48. [CrossRef]

12. Salam, R.A.; Das, J.K.; Bhutta, Z.A. Integrating nutrition into health systems: What the evidence advocates. Matern. Child Nutr. 2019, 15, e12738. [CrossRef]

13. Lang, T.; Siribaddana, S. Clinical Trials Have Gone Global: Is This a Good Thing? PLoS Med. 2012, 9, e1001228. [CrossRef] [PubMed]

14. Hodge, S. The 10/90 report on health research 2000. J. R. Soc. Promo Health 2000, 120, 197.

15. Moon, S.; Bermudez, J.; 't Hoen, E. Innovation and Access to Medicines for Neglected Populations: Could a Treaty Address a Broken Pharmaceutical R\&D System? PLoS Med. 2012, 9, e1001218. [CrossRef]

16. Rottingen, J.-A.; Chamas, C.; Goyal, L.C.; Harb, H.; Lagrada, L.; Mayosi, B.M. Securing the public good of health research and development for developing countries. Bull. World Heal. Organ. 2012, 90, 398-400. [CrossRef] [PubMed]

17. Ahmad, N.; Boutron, I.; Dechartres, A.; Durieux, P.; Ravaud, P. Geographical Representativeness of Published and Ongoing Randomized Controlled Trials. The Example of: Tobacco Consumption and HIV Infection. PLoS ONE 2011, 6, e16878. [CrossRef]

18. Perel, P.; Miranda, J.J.; Ortiz, Z.; Casas, J.P. Relation between the Global Burden of Disease and Randomized Clinical Trials Conducted in Latin America Published in the Five Leading Medical Journals. PLoS ONE 2008, 3, e1696. [CrossRef]

19. Røttingen, J.-A.; Regmi, S.; Eide, M.; Young, A.J.; Viergever, R.F.; Årdal, C.; Guzman, J.; Edwards, D.; Matlin, S.A.; Terry, R.F. Mapping of available health research and development data: What's there, what's missing, and what role is there for a global observatory? Lancet 2013, 382, 1286-1307. [CrossRef]

20. Chirac, P.; Torreele, E. Global framework on essential health R\&D. Lancet 2006, 367, 1560-1561. [CrossRef]

21. Mbuagbaw, L.; Thabane, L.; Ongolo-Zogo, P.; Lang, T. The challenges and opportunities of conducting a clinical trial in a low resource setting: The case of the Cameroon mobile phone SMS (CAMPS) trial, an investigator initiated trial. Trials 2011, 12, 145. [CrossRef]

22. Devasenapathy, N.; Singh, K.; Prabhakaran, D. Conduct of clinical trials in developing countries: A perspective. Curr. Opin. Cardiol. 2009, 24, 295-300. [CrossRef] [PubMed]

23. Dierickx, S.; O’Neill, S.; Gryseels, C.; Anyango, E.I.; Bannister-Tyrrell, M.; Okebe, J.; Mwesigwa, J.; Jaiteh, F.; Gerrets, R.; Ravinetto, R.; et al. Community sensitization and decision-making for trial participation: A mixed-methods study from the Gambia. Dev. World Bioeth. 2017, 18, 406-419. [CrossRef]

24. Costello, A. Moving to research partnerships in developing countries. BMJ 2000, 321, 827-829. [CrossRef] [PubMed]

25. Eastwood, S.V.; Hill, P.C. A gender-focused qualitative study of barriers to accessing tuberculosis treatment in the Gambia, West Africa. Int. J. Tuberc. Lung Dis. 2004, 8, 70-75.

26. O'Neill, S.; Dierickx, S.; Okebe, J.; Dabira, E.; Gryseels, C.; D'Alessandro, U.; Grietens, K.P. The Importance of Blood Is Infinite: Conceptions of Blood as Life Force, Rumours and Fear of Trial Participation in a Fulani Village in Rural Gambia. PLoS ONE 2016, 11, e0160464. [CrossRef] [PubMed]

27. Franzen, S.R.P.; Chandler, C.; Enquselassie, F.; Siribaddana, S.; Atashili, J.; Angus, B.; Lang, T. Understanding the investigators: A qualitative study investigating the barriers and enablers to the implementation of local investigator-initiated clinical trials in Ethiopia. BMJ Open 2013, 3, e003616. [CrossRef]

28. Alemayehu, C.; Mitchell, G.; Nikles, J. Barriers for conducting clinical trials in developing countries- a systematic review. Int. J. Equity Health 2018, 17, 1-11. [CrossRef]

29. Dierickx, S.; Gryseels, C.; Mwesigwa, J.; O’Neill, S.; Bannister-Tyrell, M.; Ronse, M.; Jaiteh, F.; Gerrets, R.; D’Alessandro, U.; Grietens, K.P. Factors Associated with Non-Participation and Non-Adherence in Directly Observed Mass Drug Administration for Malaria in the Gambia. PLoS ONE 2016, 11, e0148627. [CrossRef] [PubMed]

30. Bansal, N. The opportunities and challenges in conducting clinical trials globally. Clin. Res. Regul. Aff. 2012, 29, 9-14. [CrossRef]

31. Bank, W. The World Bank in the Gambia 2019. Available online: https://www.worldbank.org/en/country/gambia/overview (accessed on 30 March 2020).

32. Hennig, B.J.; Unger, S.A.; Dondeh, B.L.; Hassan, J.; Hawkesworth, S.; Jarjou, L.; Jones, K.S.; Moore, S.E.; Nabwera, H.M.; Ngum, M.; et al. Cohort Profile: The Kiang West Longitudinal Population Study (KWLPS)—A platform for integrated research and health care provision in rural Gambia. Int. J. Epidemiol. 2015, 46, e13. [CrossRef] [PubMed]

33. Ross, S.; Grant, A.; Counsell, C.; Gillespie, W.; Russell, I.; Prescott, R. Barriers to participation in randomised controlled trials: A systematic review. J. Clin. Epidemiol. 1999, 52, 1143-1156. [CrossRef]

34. Braun, V.; Clarke, V. Using thematic analysis in psychology. Qual. Res. Psychol. 2006, 3, 77-101. [CrossRef]

35. Gambia Bureau of Statistics (GBOS); ICF International. The Gambia Demographic and Health Survey 2013; Gambia Bureau of Statistics (GBOS): Banjul, Republic of Gambia; ICF International: Rockville, MD, USA, 2014. 
36. Franzen, S.R.P.; Chandler, C.; Siribaddana, S.; Atashili, J.; Angus, B.; Lang, T. Strategies for developing sustainable health research capacity in low and middle-income countries: A prospective, qualitative study investigating the barriers and enablers to locally led clinical trial conduct in Ethiopia, Cameroon and Sri Lanka. BMJ Open 2017, 7, e017246. [CrossRef]

37. McMichael, C.; Waters, M.E.; Volmink, B.J. Evidence-based public health: What does it offer developing countries? J. Public Health 2005, 27, 215-221. [CrossRef]

38. Buekens, P.; Keusch, G.; Belizan, J.; Bhutta, Z.A. Evidence-based global health. JAMA 2004, 291, 2639-2641. [CrossRef] [PubMed]

39. Volmink, J.; Siegfried, N.; Van Der Merwe, L.; Brocklehurst, P. Antiretrovirals for reducing the risk of mother-to-child transmission of HIV infection. Cochrane Database Syst. Rev. 2007, 2007, CD003510. [CrossRef]

40. Broom, A.; Hand, K.; Tovey, P. The role of gender, environment and Individual biography in shaping qualitative interview data. Int. J. Soc. Res. Methodol. 2009, 12, 51-65. [CrossRef]

41. Arendell, T. Reflections on the Researcher-Researched Relationship: A Woman Interviewing Men. Qual. Sociol. 1997, 20, 341-368. [CrossRef]

42. Malham, P.B.; Saucier, G. The conceptual link between social desirability and cultural normativity. Int. J. Psychol. 2016, 51, 474-480. [CrossRef] [PubMed] 